PREPARED FOR THE U.S. DEPARTMENT OF ENERGY, UNDER CONTRACT DE-AC02-76CH03073

PPPL-3854

PPPL-3854

UC-70

Characterization of Fast lon Absorption

of the High Harmonic Fast Wave

in the National Spherical Torus Experiment

by

A.L. Rosenberg, J.E. Menard, J.R. Wilson, S. Medley, C.K. Phillips,

R. Andre, D.S. Darrow, R.J. Dumont, B.P. LeBlanc, M.H. Redi,

T.K. Mau, E.F. Jaeger, P.M. Ryan, D.W. Swain, R.W. Harvey,

J. Egedal, and the NSTX Team

August 2003

NM|

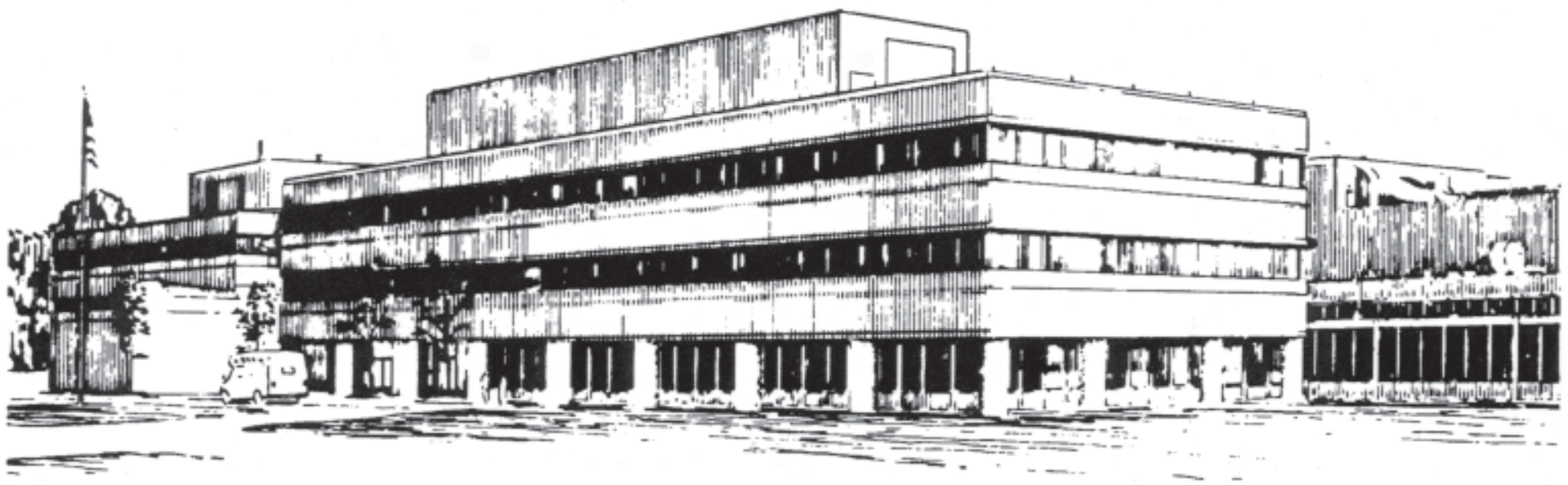

PRINCETON PLASMA PHYSICS LABORATORY PRINCETON UNIVERSITY, PRINCETON, NEW JERSEY 


\section{PPPL Reports Disclaimer}

This report was prepared as an account of work sponsored by an agency of the United States Government. Neither the United States Government nor any agency thereof, nor any of their employees, makes any warranty, express or implied, or assumes any legal liability or responsibility for the accuracy, completeness, or usefulness of any information, apparatus, product, or process disclosed, or represents that its use would not infringe privately owned rights. Reference herein to any specific commercial product, process, or service by trade name, trademark, manufacturer, or otherwise, does not necessarily constitute or imply its endorsement, recommendation, or favoring by the United States Government or any agency thereof. The views and opinions of authors expressed herein do not necessarily state or reflect those of the United States Government or any agency thereof.

\section{Availability}

This report is posted on the U.S. Department of Energy's Princeton Plasma Physics Laboratory Publications and Reports web site in Fiscal Year 2003. The home page for PPPL Reports and Publications is: http://www.pppl.gov/pub_report/

DOE and DOE Contractors can obtain copies of this report from:

U.S. Department of Energy

Office of Scientific and Technical Information

DOE Technical Information Services (DTIS)

P.O. Box 62

Oak Ridge, TN 37831

Telephone: (865) 576-8401

Fax: (865) 576-5728

Email: reports@adonis.osti.gov

This report is available to the general public from:

National Technical Information Service

U.S. Department of Commerce

5285 Port Royal Road

Springfield, VA 22161

Telephone: $1-800-553-6847$ or

(703) $605-6000$

Fax: (703) 321-8547

Internet: http://www.ntis.gov/ordering.htm 


\title{
Characterization of Fast Ion Absorption of the High Harmonic Fast Wave in the National Spherical Torus Experiment ${ }^{1}$
}

\author{
A. L. Rosenberg, J. E. Menard, J. R. Wilson, S. Medley, C. K. Phillips, R. Andre, \\ D. S. Darrow, R. J. Dumont, B. P. LeBlanc, M. H. Redi ${ }^{a}$, T. K. Mau ${ }^{b}$, E. F. Jaeger, \\ P. M. Ryan, D. W. Swain ${ }^{c}$, R. W. Harvey ${ }^{d}$, J. Egedal ${ }^{e}$, and the NSTX Team \\ ${ }^{a}$ Princeton Plasma Physics Laboratory, Princeton, NJ 08543-0451 \\ ${ }^{b}$ University of California at San Diego, La Jolla, CA 92093 \\ ${ }^{c}$ Oak Ridge National Laboratory, Oak Ridge, TN 37831 \\ ${ }^{d}$ CompX, Del Mar, CA 92014 \\ ${ }^{e}$ Plasma Science and Fusion Center, Massachusetts Institute of Technology, Cambridge, MA 02139
}

\begin{abstract}
Ion absorption of the high harmonic fast wave in a spherical torus is of critical importance to assessing the viability of the wave as a means of heating and driving current. Analysis of recent NSTX shots has revealed that under some conditions when neutral beam and RF power are injected into the plasma simultaneously, a fast ion population with energy above the beam injection energy is sustained by the wave. In agreement with modeling, these experiments find the RF-induced fast ion tail strength and neutron rate at lower B-fields to be less enhanced, likely due to a larger $\beta$ profile, which promotes greater off-axis absorption where the fast ion population is small. Ion loss codes find the increased loss fraction with decreased B insufficient to account for the changes in tail strength, providing further evidence that this is an RF interaction effect. Though greater ion absorption is predicted with lower $k_{\|}$, surprisingly little variation in the tail was observed, along with a small neutron rate enhancement with higher $k_{\|}$. Data from the neutral particle analyzer, neutron detectors, $\mathrm{X}$-ray crystal spectrometer, and Thomson scattering is presented, along with results from the TRANSP transport analysis code, ray-tracing codes HPRT and CURRAY, full-wave code and AORSA, quasi-linear code CQL3D, and ion loss codes EIGOL and CONBEAM.
\end{abstract}

\section{INTRODUCTION}

Interaction between the high harmonic fast wave (HHFW) and energetic particles in a spherical torus (ST) [1] is a new and important research area. A fast ion population of fusion-born alpha particles will be found in a reacting plasma, along with energetic ions from neutral beam injection (NBI) in some scenarios. HHFW is currently being

1) This work was supported by the United States Department of Energy under Contract No. DE-AC02$76 \mathrm{CH} 03073$. 

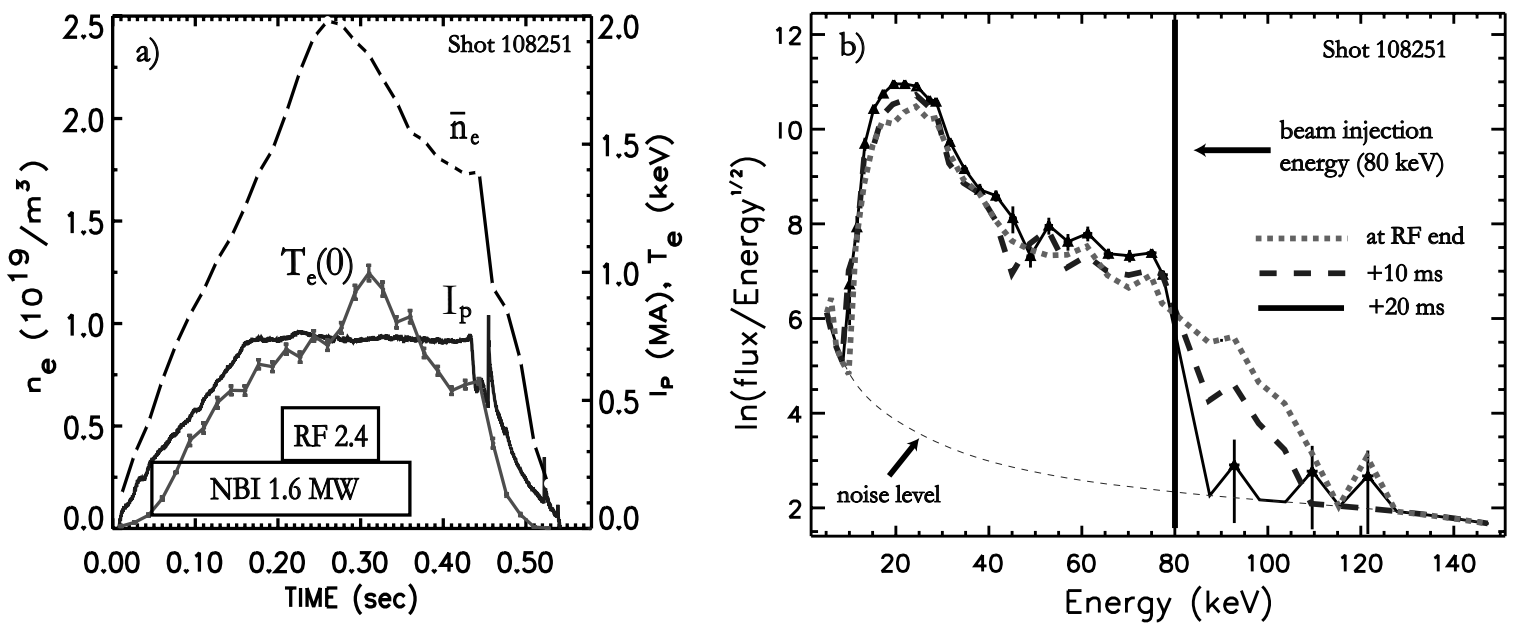

FIGURE 1. a) Typical line-averaged density, temperature, plasma current, NBI, and RF power profiles for scans in recent experiments. b) Neutral particle analyzer data for NSTX shot 108251, launched $k_{\|}$ $=14 \mathrm{~m}^{-1}$ (heating phasing), after RF turns off at $\mathrm{t}=320 \mathrm{~ms}$. Fast ion population above $80 \mathrm{keV}$ beam injection energy collapses to a typical no-RF distribution within $20 \mathrm{~ms}$.

explored as a means of heating and driving plasma current. In NSTX's most recent campaigns, a clear fast ion tail was observed on the neutral particle analyzer (NPA) when HHFW and NBI were active simultaneously. Neutron detector and ion loss probe signals provided further evidence for interaction. This occurred for nearly every shot there was a significant overlap in RF and NBI power traces. Ray-tracing was used to analyze these shots, and found absorption by fast ions to be competitive with electron absorption. Measured neutron rates for similar RF and no-RF shots were also compared with predicted rates, and a significant RF-induced enhancement was found, consistent with the enhanced tail.

\section{EXPERIMENTAL STUDIES}

For all shots analyzed, the neutral beam injected deuterium into the plasma at $\mathrm{E}_{\text {beam }} \approx$ $80 \mathrm{keV}, \mathrm{P}_{\text {beam }} \approx 1.6 \mathrm{MW}$. Without RF, the energy spectrum observed by the NPA dropped out above $\sim 80 \mathrm{keV}$. With RF, the energy spectrum extended to $\sim 130 \mathrm{keV}$. Furthermore, after RF turnoff with NBI remaining active, the tail decayed to the no-RF spectrum on a time scale comparable to that for decay of a beam-only distribution, as seen in Figure 1. The ZnS and fission neutron detectors also saw a significant signal enhancement with RF. This signal began dropping immediately upon RF turnoff as well. As shown in Figure 2a, for similar shots with and without RF, within 25 ms of RF turnoff the enhanced neutron rate decays to the no RF value.

To further examine the fast ion absorption dependence on various parameters, scans in $B_{0}$ and $k_{\|}$were performed. These shots all had similar electron temperature and density profiles, so the scan in $B_{0}$ effectively became a $\beta_{t}$ scan. As demonstrated in Figure 3, the neutron rate was found to decrease with decreasing toroidal field, and the fast ion tail on the NPA dropped to nearly a no-RF spectrum. In Ref. [2], total 

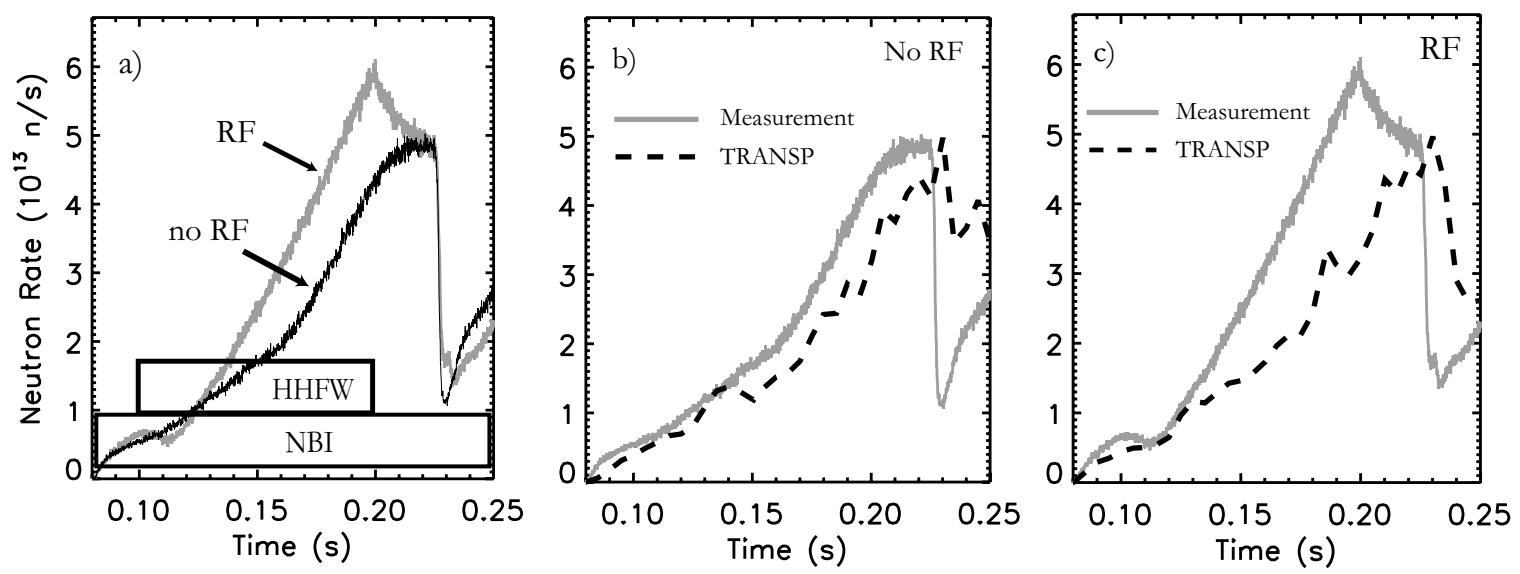

FIGURE 2. a) Neutron rates for NSTX shots 105906 (no RF) and 105908 (RF). b) Neutron rate for no RF vs. TRANSP prediction. After RF turns off, rate decays close to measured and predicted no RF value. c) Measured neutron rate for RF shot significantly exceeds TRANSP prediction without RF input.

absorption is predicted to increase with $\beta$, and because the fast ion population is quite centralized, these experimental results are consistent with theory as less power from an antenna on the outboard side of the plasma would be available to core fast ions in a high $\beta$ shot. Though greater ion absorption is predicted with lower $k_{\|}[3,4]$, surprisingly little variation in the tail was observed, along with a small neutron rate enhancement with higher $k_{\|}$. This discrepancy may be due to different edge coupling conditions at different antenna phasings. The antenna performance and reliability have recently been significantly improved, so this will be reinvestigated in the next NSTX campaign.

\section{THEORETICAL STUDIES}

For analysis, the TRANSP [5] transport analysis code was used to calculate fast ion energy and particle density profiles, and this information was used to estimate an effective Maxwellian temperature for the fast ion population. These profiles, along with EFIT and Thomson data, were fed into HPRT, a 2-D ray-tracing code which uses the full hot plasma dielectric with complex $k$ to compute power deposition profiles along the hot electron/cold ion ray path [3]. As shown in Figs. 4a and 5a, fast ion absorption was calculated to be competitive with electron absorption in sustained neutral beam shots, often taking $\sim 35 \%$ of the total RF power. Figures $4 a-c$ show that these results and profiles matched those of CURRAY [6], an independently developed ray-tracing code, and AORSA [7], an all orders full wave code, reasonably well for RF+NBI equilibria. CQL3D [8], a quasi-linear code which currently uses a model of the fast ion distribution function rather than an effective Maxwellian, has also calculated 35\% ion absorption for this shot, and finds a similar ion deposition profile. A comparison of typical ray paths in HPRT vs. wave front propagation calculated by AORSA is shown in Figure 6. Both codes launch waves from identical antenna geometry on the outboard side of the plasma. The flow of these paths are remarkably similar considering the quite different methods of calculation. It also helps demonstrate the importance of including 

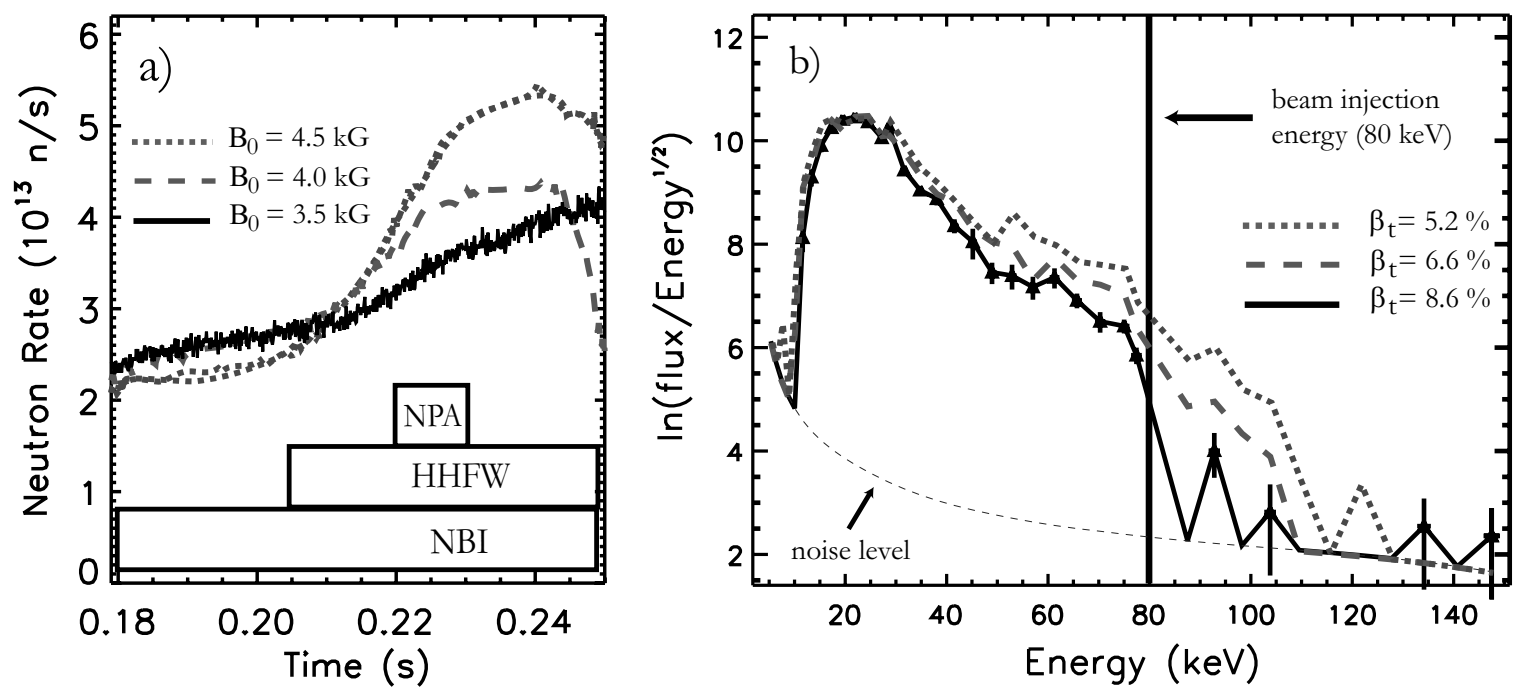

FIGURE 3. a) Neutron rates for otherwise similar NSTX shots at $B_{0}=3.5,4.0$, and $4.5 \mathrm{kG}$, which correspond to $\beta_{t}=5.2,6.6$, and $8.6 \%$, respectively. b) NPA signals at $\mathrm{R}_{\tan }=70 \mathrm{~cm}$ for $B_{0}$ scan, averaged over time window displayed in a). The larger $\beta$ profile at lower $B_{0}$ may promote greater off-axis electron absorption, reducing the fraction of power available to the centralized fast ion population.
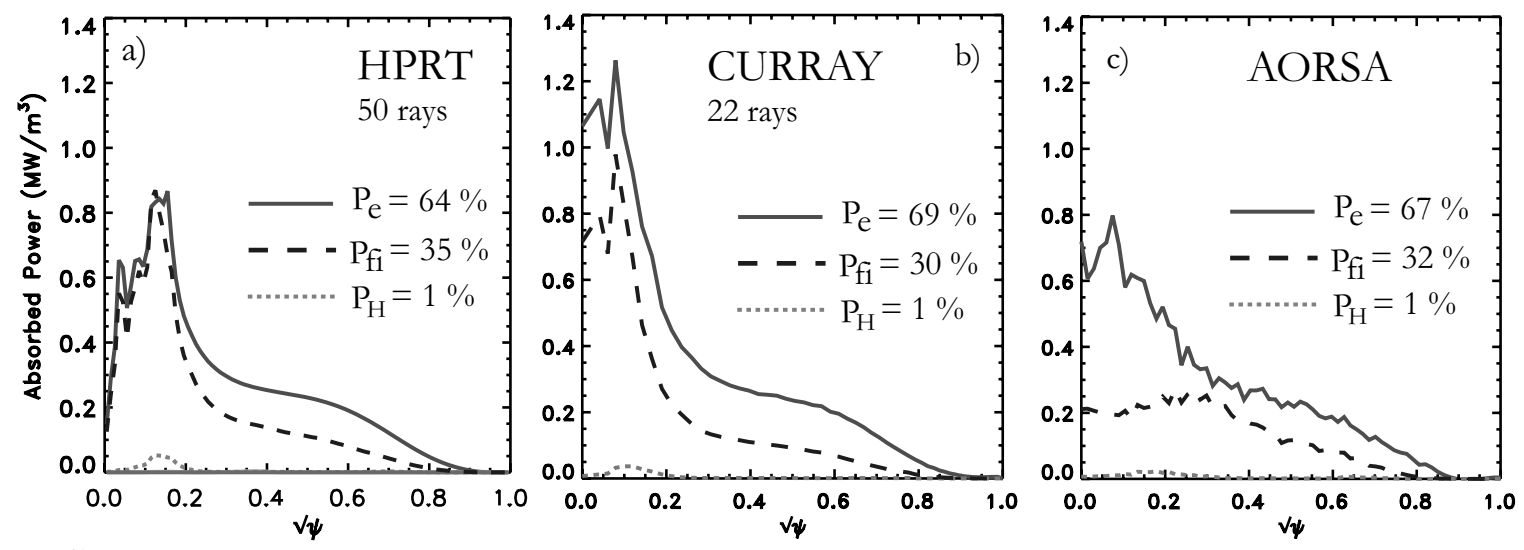

FIGURE 4. Power deposition profiles for NSTX shot 108251, $\mathrm{t}=235 \mathrm{~ms}, n_{\phi}=24$ from a) HPRT, 50 rays, b) CURRAY, 22 rays, and c) AORSA. Good agreement is found in fractional absorption and profiles between codes for RF+NBI shots. 

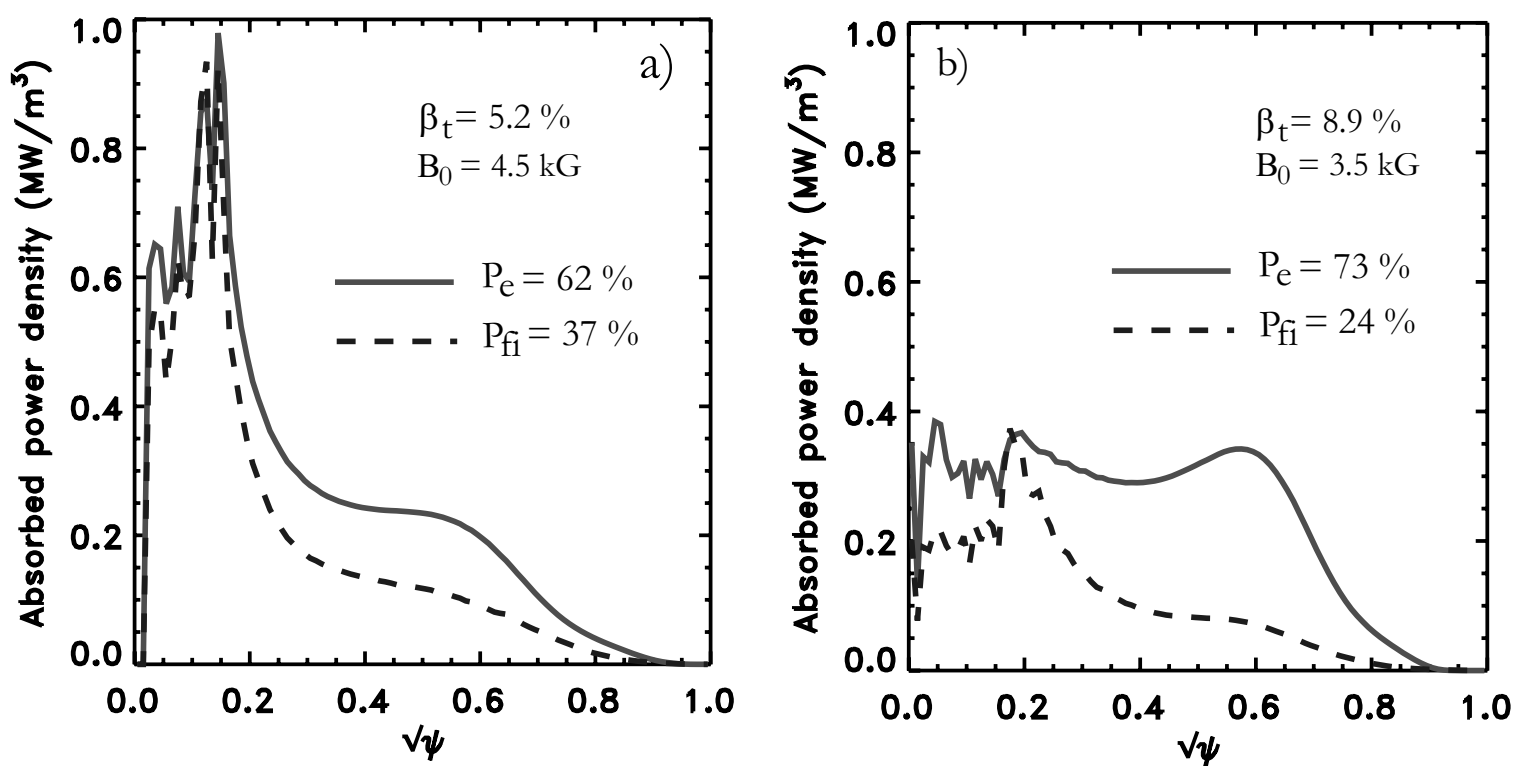

FIGURE 5. a) HPRT power deposition profiles for NSTX shot 108250, $\mathrm{t}=230 \mathrm{~ms}$, $B_{0}=4.5 \mathrm{kG}, \beta_{t}=5.2 \%$. b) Shot $108252, \mathrm{t}=230 \mathrm{~ms}, B_{0}=3.5 \mathrm{kG}, \beta_{t}=8.9 \%$. Lower on-axis absorption is calculated for lower $B$, higher $\beta$, in agreement with neutron rate and NPA signals.

2D effects in absorption calculations for ST equilibria. Figure 5 shows HPRT calculated deposition profiles for the experimental magnetic field scan. Lower on-axis absorption is calculated for lower $B$, or higher $\beta$, in agreement with the neutron rate and NPA signals in Figure 3, as the greater off-axis electron absorption in higher $\beta$ shots would prevent as much RF power from reaching the bulk of the fast ion population near the magnetic axis. An increased fast ion loss fraction at lower $B$ may also contribute to suppression of the observed tail, so loss codes EIGOL [9], which follows the full fast ion orbit, and CONBEAM [10], which follows the guiding center of the orbits and accounts for finite larmor radius effects, were used to determine the significance of this factor. For $120 \mathrm{keV}$ ions, EIGOL calculates a loss fraction of $17 \%$ for a $B_{0}=4.5 \mathrm{kG}$ equilibrium - NSTX shot $108250, \mathrm{t}=235 \mathrm{~ms}$, and $23 \%$ for $B_{0}=3.5 \mathrm{kG}$ - shot 108252 , $\mathrm{t}=235 \mathrm{~ms}$. CONBEAM calculates a loss fraction of $21 \%$ for $B_{0}=4.5 \mathrm{kG}$, and $25 \%$ for $B_{0}=3.5 \mathrm{kG}$. According to the NPA data, the tail is suppressed by at least a factor of 8 between high and low field, so the tail reduction is more likely due to an RF effect.

Without providing RF input in either case, TRANSP was also used to calculate the neutron rates for similar RF and no-RF shots. As shown in Figure 2, the measured rate matched the prediction well in the no-RF case, and for the RF shot grew to nearly double the predicted rate. It then decayed to approximately the computed rate after RF turnoff. Figure 7a demonstrates that a single effective Maxwellian, matching fast ion particle and energy density exactly, fits the TRANSP $f(E)$ remarkably well, however it exceeds the neutron rate calculated from the TRANSP distribution function by $\sim 20 \%$. Figure $7 \mathrm{~b}$ shows that the single Maxwellian has too large of a contribution to $\int_{0}^{E} d E f(E) \sigma v$, which is proportional to the neutron rate, above the beam injection energy, $80 \mathrm{keV}$. To model this neutron rate enhancement, multiple Maxwellians may 

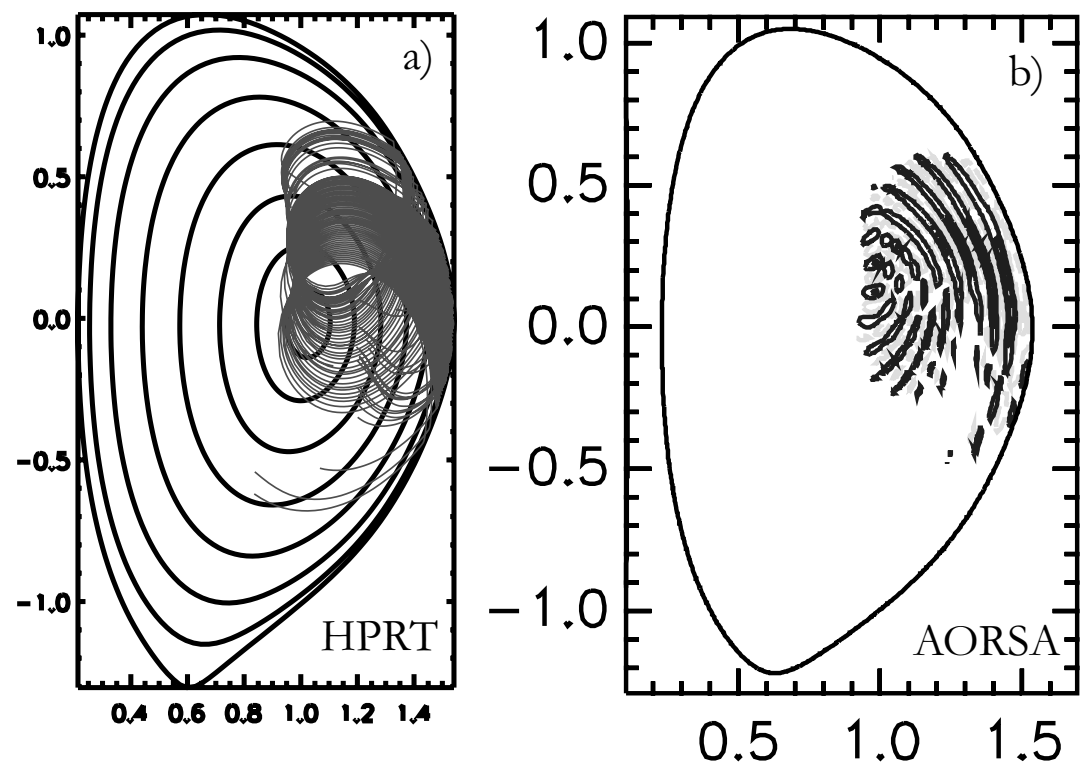

FIGURE 6. a) 50 HPRT ray paths, with initial positions distributed evenly over poloidal range of antenna, for NSTX shot $108251, \mathrm{t}=235 \mathrm{~ms}, \beta=5.2 \%, n_{\phi}=24$. Each ray stops when $99 \%$ of its power is absorbed. b) AORSA wave fronts for same shot.
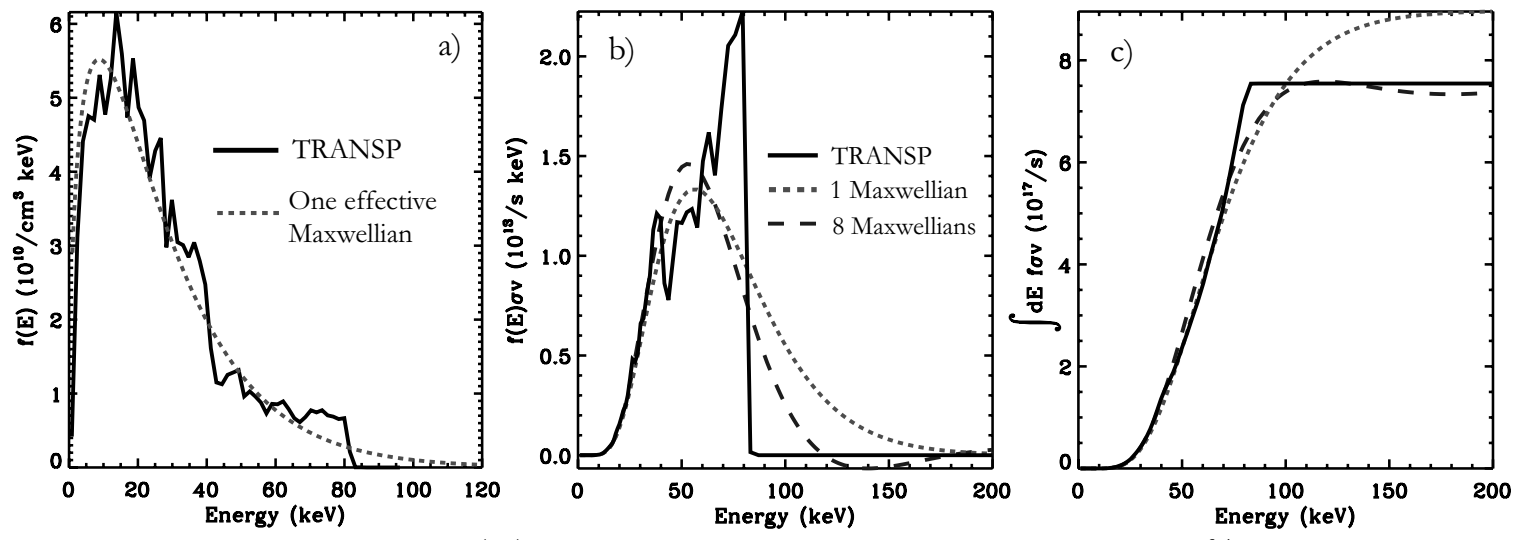

FIGURE 7. a) TRANSP $f(E)$ for NSTX shot $108251, \mathrm{t}=235 \mathrm{~ms}, \mathrm{r} / \mathrm{a}=3 \%$ vs. an effective Maxwellian matching its total energy and particle density exactly. The neutron rate from this Maxwellian exceeds TRANSP's by $\sim 20 \%$. b) TRANSP $f(E) \sigma v$ vs. one effective Maxwellian, as well as an 8 Maxwellian $f(E)$. c) TRANSP $\int_{0}^{E} d E f(E) \sigma v \propto$ neutron rate vs. other two functions. Although $f(E) \sigma v$ cannot be fit well with isotropic, unshifted Maxwellians used in most wave power absorption codes, total neutron rate can, and $\sim 80 \%$ of neutrons created below energy range of largest discrepancy, so using this $f(E)$ to estimate neutron rate may have some validity. 
provide a more accurate estimate. Although $f(E) \sigma v$ cannot be fit well with isotropic, unshifted Maxwellians used in most wave power absorption codes, total neutron rate can. As shown in Figure $7 \mathrm{c}, \sim 80 \%$ of neutrons are created below the energy range of largest discrepancy in $f(E) \sigma v$, so using this $f(E)$ to estimate neutron rate may have some validity. The next steps in calculating a rough neutron rate enhancement are to compute the fast ion power deposition profiles and confinement times for each Maxwellian, perturb the temperature of each accordingly, and recalculate the neutron rate with the pertubed distribution function. CQL3D may also be used to calculate this enhancement, and will soon be able to read in the TRANSP distribution function to provide more quantitative agreement between experiment and theory.

For equilibria without fast ions, low $n_{\phi} \approx 6$, and high thermal $T_{i}(0) \approx 2 \mathrm{keV}$, less agreement between wave absorption codes has been found, often differing in bulk deuterium absorption by a factor of $\sim 2$, with HPRT consistently calculating less than CURRAY or AORSA. This is surprising considering the level of agreement for the fast ion shots which actually had $T_{i}(0) \approx 1.5 \mathrm{keV}$. CURRAY and HPRT have been found to agree in ray path and deposition profile quite well for $\mathrm{RF}+\mathrm{NBI}$ and equilibria dominated by electron absorption. A possible explanation is that HPRT is using the complex $k$ in its dielectric tensor, whereas CURRAY does not, and the impact only arises in this particular parameter regime. As outlined in [11], HPRT's equation for absorbed power density

$$
\frac{\partial W_{p s}}{\partial t}=\mathbf{E}_{\mathbf{1}}^{*} \cdot \mathbf{j}_{\mathbf{s}}-\nabla \cdot \mathbf{T}_{\mathbf{s}}
$$

thus includes the latter kinetic flux term:

$$
\nabla \cdot \mathbf{T}_{\mathbf{s}}=\frac{\omega}{\mathbf{8 \pi}} \mathbf{E}_{\mathbf{1}}^{*} \cdot\left(\mathbf{k}_{\mathbf{i}} \cdot \frac{\partial}{\partial \mathbf{k}} \overline{\bar{\epsilon}}_{\mathbf{H s}} \cdot \mathbf{E}_{\mathbf{1}}\right) \mathrm{e}^{\mathbf{2} \phi_{\mathrm{i}}} .
$$

while CURRAY, because it keeps $k$ real in the evaluation of its dielectric tensor, sets $\partial W_{p s} / \partial t=\mathbf{E}_{1}^{*} \cdot \mathbf{j}_{\mathrm{s}}$. It should be noted that a rigorous derivation from the energy moment of the Vlasov equation to this form of the kinetic flux term with complex $k$ has yet to be performed. Noting that there is currently discrepancy between theory and experiment in the $k_{\|}$scan (there has yet to be any experimental evidence of significant bulk ion absorption at all in NSTX), and there is a discrepancy between ray-tracing codes at lower $k_{\|}$, a breakdown of the theory at lower $k_{\|}$should not be ruled out.

\section{CONCLUSIONS}

Analysis of recent NSTX shots has revealed that under some conditions when neutral beam and RF power are injected into the plasma simultaneously, a fast ion population with energy above the beam injection energy is sustained by the wave. In agreement with modeling, these experiments find the RF-induced fast ion tail strength and neutron rate at lower B-fields to be less enhanced, likely due to a larger $\beta$ profile, which promotes greater off-axis absorption where the fast ion population is small. Ion 
loss codes EIGOL and CONBEAM find the increased loss fraction with decreased B insufficient to account for the changes in tail strength, providing further evidence that this is an RF interaction effect. Though greater ion absorption is predicted with lower $k_{\|}$, surprisingly little variation in the tail was observed, along with a small neutron rate enhancement with higher $k_{\|}$. Comparison between ray-tracing codes HPRT and CURRAY, full-wave code AORSA, and quasilinear code CQL3D have found good agreement in deposition profile and fractional absorption for RF+NBI shots. Ray paths and wave fronts match remarkably well between the ray tracing codes and AORSA. Less agreement is found between HPRT and CURRAY in lower $k_{\|}$, no-NBI equilibria with high thermal ion temperature. An effective Maxwellian matches the fast ion distribution function below $\sim 60 \mathrm{keV}$, but to match the neutron rate more Maxwellians are needed. Future work includes attempting to gain more quantitative agreement between experiment and theory by determining how the fast ion distribution function is perturbed by RF and recalculating the neutron rate, either by using several Maxwellians or CQL3D.

\section{REFERENCES}

1. Y.-K. M. Peng and D. J. Strickler, Nucl. Fusion 26, 769 (1986).

2. M. Ono, Phys. Plasmas 2, 4075 (1995).

3. J. Menard, R. Majeski, R. Kaita, M. Ono, and T. Munsat, Phys. Plasmas 6, 2002 (1999).

4. C. N. Lashmore-Davies, V. Fuchs, and R. A. Cairns, Phys. Plasmas 5, 2284 (1998).

5. J. P. H. E. Ongena, M. Evrard, and D. McCune, Fusion Technology 33, 181 (1998).

6. T. K. Mau, C. C. Petty, M. Porkolab, and W. W. Heidbrink, Modeling of fast wave absorption by beams in DIII-D discharges, in Radio Frequency Power in Plasmas: 13th Topical Conference, AIP Conference Proceedings 485, page 148, Annapolis, Maryland, 1999, American Institute of Physics, New York.

7. E. F. Jaeger, L. A. Berry, E. D'Azevedo, D. B. Batchelor, and M. D. Carter, Advances in full-wave modeling of rf heated, multi-dimensional plasmas, in Radio Frequency Power in Plasmas: 14th Topical Conference, AIP Conference Proceedings 595, page 369, Oxnard, California, 2001, American Institute of Physics, New York.

8. R. W. Harvey and M. G. McCoy, The CQL3D Fokker-Planck code, in Proceedings of IAEA Technical Committee Meeting on Advances in Simulation and Modeling of Thermonuclear Plasmas, Montreal, 1992, available through USDOC, NTIS no. DE9300962.

9. D. Darrow, R. Akers, D. Mikkelsen, S. Kaye, and F. Paoletti, Modeling of neutral beam ion loss from NSTX plasmas, in Proceedings of the 6th IAEA Technical Committee Meeting on Energetic Particles in Magnetic Confinement Systems, page 109, Ibaraki-ken, Japan, 2000, Japan Atomic Energy Res. Inst.

10. J. Egedal, M. H. Redi, D. S. Darrow, and S. M. Kaye, Phys. Plasmas 10 (2003).

11. J. E. Menard, C. K. Phillips, and T. K. Mau, Ion absorption effects in high-harmonic fast wave ray tracing theory, in Radio Frequency Power in Plasmas: 13th Topical Conference, AIP Conference Proceedings 485, page 345, Annapolis, Maryland, 1999, American Institute of Physics, New York. 


\section{External Distribution}

Plasma Research Laboratory, Australian National University, Australia

Professor I.R. Jones, Flinders University, Australia

Professor João Canalle, Instituto de Fisica DEQ/IF - UERJ, Brazil

Mr. Gerson O. Ludwig, Instituto Nacional de Pesquisas, Brazil

Dr. P.H. Sakanaka, Instituto Fisica, Brazil

The Librarian, Culham Laboratory, England

Mrs. S.A. Hutchinson, JET Library, England

Professor M.N. Bussac, Ecole Polytechnique, France

Librarian, Max-Planck-Institut für Plasmaphysik, Germany

Jolan Moldvai, Reports Library, Hungarian Academy of Sciences, Central Research Institute for Physics, Hungary

Dr. P. Kaw, Institute for Plasma Research, India

Ms. P.J. Pathak, Librarian, Institute for Plasma Research, India

Ms. Clelia De Palo, Associazione EURATOM-ENEA, Italy

Dr. G. Grosso, Instituto di Fisica del Plasma, Italy

Librarian, Naka Fusion Research Establishment, JAERI, Japan

Library, Laboratory for Complex Energy Processes, Institute for Advanced Study, Kyoto University, Japan

Research Information Center, National Institute for Fusion Science, Japan

Dr. O. Mitarai, Kyushu Tokai University, Japan

Dr. Jiangang Li, Institute of Plasma Physics, Chinese Academy of Sciences, People's Republic of China

Professor Yuping Huo, School of Physical Science and Technology, People's Republic of China

Library, Academia Sinica, Institute of Plasma Physics, People's Republic of China

Librarian, Institute of Physics, Chinese Academy of Sciences, People's Republic of China

Dr. S. Mirnov, TRINITI, Troitsk, Russian Federation, Russia

Dr. V.S. Strelkov, Kurchatov Institute, Russian Federation, Russia

Professor Peter Lukac, Katedra Fyziky Plazmy MFF UK, Mlynska dolina F-2, Komenskeho Univerzita, SK-842 15 Bratislava, Slovakia

Dr. G.S. Lee, Korea Basic Science Institute, South Korea

Institute for Plasma Research, University of Maryland, USA

Librarian, Fusion Energy Division, Oak Ridge National Laboratory, USA

Librarian, Institute of Fusion Studies, University of Texas, USA

Librarian, Magnetic Fusion Program, Lawrence Livermore National Laboratory, USA

Library, General Atomics, USA

Plasma Physics Group, Fusion Energy Research Program, University of California at San Diego, USA

Plasma Physics Library, Columbia University, USA

Alkesh Punjabi, Center for Fusion Research and Training, Hampton University, USA

Dr. W.M. Stacey, Fusion Research Center, Georgia Institute of Technology, USA

Dr. John Willis, U.S. Department of Energy, Office of Fusion Energy Sciences, USA

Mr. Paul H. Wright, Indianapolis, Indiana, USA 
The Princeton Plasma Physics Laboratory is operated by Princeton University under contract with the U.S. Department of Energy.

\author{
Information Services \\ Princeton Plasma Physics Laboratory \\ P.O. Box 451 \\ Princeton, NJ 08543
}

Phone: 609-243-2750

Fax: 609-243-2751

e-mail: pppl_info@pppl.gov

Internet Address: http://www.pppl.gov 